\title{
ПОЛИТИЧЕСКАЯ СОЦИОЛОГИЯ
}

\author{
DOI: $10.24290 / 1029-3736-2021-27-1-251-262$
}

\section{ПОЛИТИЧЕСКИЙ МЕХАНИЗМ УПРАВЛЕНИЯ США В ОЦЕНКАХ ОБЩЕСТВЕННОГО МНЕНИЯ}

С.Н. Большаков, докт. полит. наук, докт. эконом. наук, проф., проректор ГАО ВО ЛО “Ленинградский государственный университет имени А.С. Пушкина”, Петербургское ш., 10, Санкт-Петербург, Российская Федерация, 196605*

В статье рассматриваются актуальные проблемы функционирования демократических институтов в США. Анализируются последствия выборов президента и их влияние на общественное мнение. В условиях растущего напряжения по отночению к демократии во всем мире и демократическим иенностям, граждане США обычно соглашаются с важностью демократических идеалов и иенностей, которые важны для Соединенных Штатов. Результаты исследования также демонстрируют осознание американским обществом объективного наличия необходимой критики. Большинство респондентов подчеркивает свои знания об основных фактах о политической системе и демократии в США. Большинство опроченных респондентов говорит, что необходимы "значительные изменения" в фундаментальной структуре органов исполнительной власти американского правительства, чтобы оно эфбективно работало в нынешнее время.

В статье констатируется сложность происходящих внутриполитических процессов в США, наличие существующих противоречий и раскол общественного мнения относительно стабильности демократических механизмов функиионирования политической системы США. Сложность религиозных, начиональных, сочиальных и иных противоречий общественного развития подняла на поверхность общественных дискуссий комплекс проблем динамики политического развития и государственного механизма управления.

Ключевые слова: демократия, политическая система, политический процесс, государственное управление, общественное мнение.

\section{THE POLITICAL MECHANISM OF GOVERNANCE IN THE UNITED STATES PUBLIC OPINION ASSESSMENTS}

Bolshakov Sergey N., Dr. Polit. Sciences, Dr. Economy. Sci., Prof., Vice-Rector of GAO VO LO "Leningrad State University named after A.S. Pushkin", Petersburg highway, 10, St. Petersburg, Russian Federation, 196605, e-mail: Snbolshakov@gmail.com

\footnotetext{
* Большаков Сергей Николаевич, e-mail: Snbolshakov@gmail.com
} 
The article discusses the current problems offunctioning democratic institutions in the United States. The consequences of presidential elections and their influence on public opinion are analyzed. In the face of growing tensions toward world democracy and democratic values, US citizens usually agree on the importance of democratic ideals and values that are important to the United States. The results of the study also demonstrate the awareness of American society of the objective existence necessary criticism. Most respondents emphasize their knowledge of basic facts about the political system and democracy in the United States. The majority of respondents said that "significant changes" are necessary in the fundamental structure of the executive bodies of the American government in order for it to work effectively at the present time.

The article states the complexity of the ongoing domestic political processes in the United States, the existence of existing contradictions and the split of public opinion regarding the stability of democratic mechanisms of the functioning of the US political system. The complexity of religious, national, social and other contradictions of social development brought to the surface of public debate a complex of problems of the dynamics of political development and the state mechanism of government.

Key words: democracy, political system, political process, government, public opinion.

Многие исследователи политической системы США отмечают усиление процессов децентрализации государства как определенный объективный процесс, связанный с расширением масштабов и государства, и функций государства, и активизации роли государства как перераспределительного механизма национального дохода. Новейший период американской истории характеризуется политикой децентрализации, когда центральное правительство сосредоточивает свою деятельность на задачах внешней политики, обороны, обеспечения социальных гарантий обществу1. В период президентства Дж. Буша-старшего проведены реформы по сокращению государственного аппарата управления, снижение уровня федерального контроля над расходованием федеральных ресурсов получаемых штатами и т.п. ${ }^{2}$

В последующие периоды правления демократов активизировался потенциал рыночных механизмов, институционализировались условия роста конкурентоспособности страны, динамики ее развития. В последующее время республиканские администрации Белого дома сосредоточились на реализации государственной политики, базиру-

${ }^{1}$ Миронюк М.Г. Современный федерализм. Сравнительный анализ. М., 2008. C. 136-143.

${ }^{2}$ Quigley C.N. Constitutional democracy // Center for Civic Education. 2018. URL: http://www.civiced.org/resources/publications/resource-materials/390-constitutionaldemocracy (accessed: 09.01.2019). 
ющейся на усилении самостоятельности штатов, местных органов власти в осуществлении социально-экономической политики, поощрении деловой активности бизнеса ${ }^{3}$.

Различные исследования, активно проводимые многими организациями в США (Университет Рочестера, Йельский университет, Дартмутский колледж и др.), в том числе на основе результатов репрезентативных социологических работ негативно оценивают развитие американской демократии ${ }^{4}$. Дж. Кэри и С. Стоукс делают однозначный вывод о снижении эффективности американских демократических институтов: их опрос экспертов-политологов зафиксировал, что 15\% из них считают последние выборы "мошенническими" ". Также исследование С. Стоукс из Иельского университета показало, что по мнению экспертов, единственный принцип, по которому наблюдается существенное улучшение, заключается в “расследовании правоохранительными органами деятельности государственных должностных лиц или их партнеров, которое свободно от политического влияния или вмешательства"6. Все это доказывает сложность и определенную проблематичность функционирования демократических институтов США, полярность общественного мнения, расколотого президентскими выборами 2016 г.

Стабильность работы “двухтактного” партийного механизма США была нарушена сложными и политически-активными президентскими выборами в 2016 г. На выборах 58-го президента США победил кандидат от республиканской партии, бизнесмен-миллиардер Д. Трамп, набрав 306 голосов выборщиков, против 232 голосов выборщиков за Х. Клинтон, представителя партии демократов. Сама предвыборная компания и стратегия ее проведения обеими партиями в США акцентировали внимание многих политологов, исследователей в сфере государственного управления на возможных недостатках не столько самих процедурных элементов избирательной системы, сколько на недостатках функционирования политической системы США, адекватности исполнительной и представительной системы США вызовам времени ${ }^{7}$

${ }^{3}$ Миронюк М.Г. Указ. соч.

${ }^{4}$ Stone T. The Trump kleptocracy. The presidency is officially a cash grab - and a pitstop on the way to autocracy // Medium politics. URL: https://medium.com/s/story/ the-trump-kleptocracy-969c3ef9b4b3 (accessed: 30.12.2018).

${ }^{5}$ Stokes S.C., Clayton K.P., Helmke G. American democracy after Trump's first year // Bright Line Watch. 2018. 8 Febr.

${ }^{6}$ Ibid.

${ }^{7}$ Wike R., FetterolfJ. Liberal democracy's crisis of confidence // Journal of Democracy. 2018. N 29 (4). P. 136-150. 
В условиях растущего напряжения по отношению к демократии во всем мире и демократическим ценностям граждане США обычно соглашаются с важностью демократических идеалов и ценностей, которые важны для Соединенных Штатов. Но по большей части американцы видят, что страна не справляется с этими идеалами внутри страны, согласно новому исследованию мнений о сильных и слабых сторонах ключевых аспектов американской демократии и политической системы ${ }^{8}$.

Интересным представляется анализ результатов опроса общественного мнения о проблемах демократии и политической системы США, осуществленного известным исследовательским центром в Вашингтоне “Pew center", который был проведен в социальных сетях с 29 января по февраль 2018 г., с охватом выборки 4656 респондентов США, опрос был дополнен телефонным опросом 7-14 марта 2018 г. среди 1466 респондентов США 9 .

Результаты исследования показывают активность публичной критики политической системы США, охватывающей всевозможные аспекты: от неспособности государства привлечь к ответственности выборных должностных лиц до отсутствия прозрачности правительств. $30 \%$ респондентов соглашаются с политической действительностью американской политической системы, даже если не во всем согласны с политической, фактически сложившейся ситуацией в США.

Результаты социологических исследований, проведенных исследовательским центром "Pew center" в США, демонстрируют существенные недостатки, которые охватывают большую часть основных элементов механизма американской демократии. Подавляющая часть опрошенных американцев (84\%) говорит, что очень важно, чтобы “уважались права и свободы всех людей”, менее половины респондентов (47\%) говорят, что этот показатель описывает США “очень хорошо” или “в некоторой степени хорошо”; немного больше респондентов (53\%) ставят негативные/отрицательные оценки ${ }^{10}$.

Несмотря на эту критику большинство американцев подчеркивают, что демократия работает в Соединенных Штатах на высоком уровне, хотя относительно немногие респонденты говорят, что она работает “очень хорошо”. В то же время существует широкая общественная поддержка для внесения радикальных изменений в

\footnotetext{
${ }^{8}$ The public, the political system and American democracy // Trust, Facts, and Democracy. Pew Research Center. URL: http://www.people-press.org/2018/04/26/the-public-thepolitical-system-and-american-democracy/ (accessed: 09.01.2019).

${ }^{9}$ Ibid.

${ }^{10}$ Ibid.
} 
политическую систему США: $61 \%$ американцев подчеркивают, что необходимы “существенные изменения” в “фундаменте и структуре” правительства США, чтобы оно работало более эффективно в настоящее время ${ }^{11}$.

Общественное мнение посылает смешанные сигналы о том, как следует изменить американскую политическую систему, и никакие конструктивные предложения в настоящее время не привлекают поддержку двухпартийного механизма США. С точки зрения того, как много специфических аспектов политической системы США оказывают влияние, этим выражается недовольство сложившейся политической системой: и республиканцами, и демократами ${ }^{12}$.

Большинство респондентов США (74\%) отмечает, что военное руководство в США публично не поддерживает конкретно какую-то партию, и почти столько же (73\%) респондентов отмечает, что демократический принцип “люди могут свободно и мирно протестовать” описывает США максимально конкретно.

В целом, как показывает проведенное в 2018 г. социологическое исследование "Pew center", существует определенное несоответствие между установками общественного мнения на перспективы американской демократии и представлениями американского общества о том, выполняются ли демократические установки. Что касается 23 исследованных индикаторов, оценивающих демократию, политическую систему и выборы в целом в Соединенных Штатах, - каждый из показателей широко воспринимается общественностью как важный: по 8 индикаторам из 23 большинство респондентов США говорит, что в США с демократией “все очень хорошо"13.

Результаты проведенного исследования позволяют сделать определенные выводы. Так, в частности, исследование продемонстрировало наличие смешанных оценок респондентами изменений в политической системе США ${ }^{14}$. Социологический опрос зафиксировал тренды возможных изменений в организации и восприятия общественностью институтов представительной демократии в Соединенных Штатах. Большинство американцев категорически отвергают идею внесения поправок в Конституцию, преследующих своей целью предоставление штатам с большим населением большего числа мест в Сенате США, существует незначительная поддержка расширения

11 The public, the political system and American democracy.

12 The partisan divide on political values grows even wider // Trust, Facts, and Democracy. Pew Research Center. URL: http://www.people-press.org/2017/10/05/the-partisandivide-on-political-values-grows-even-wider/ (accessed: 09.01.2019).

13 The partisan divide on political values grows even wider; The public, the political system and American democracy.

14 The public, the political system and American democracy. 
состава Палаты представителей. Большинство респондентов США (55\%) поддерживает изменение способа избрания президентов, чтобы президентом становился тот кандидат, который получил бы наибольшее количество голосов по всей стране, а не большинство в Коллегии выборщиков.

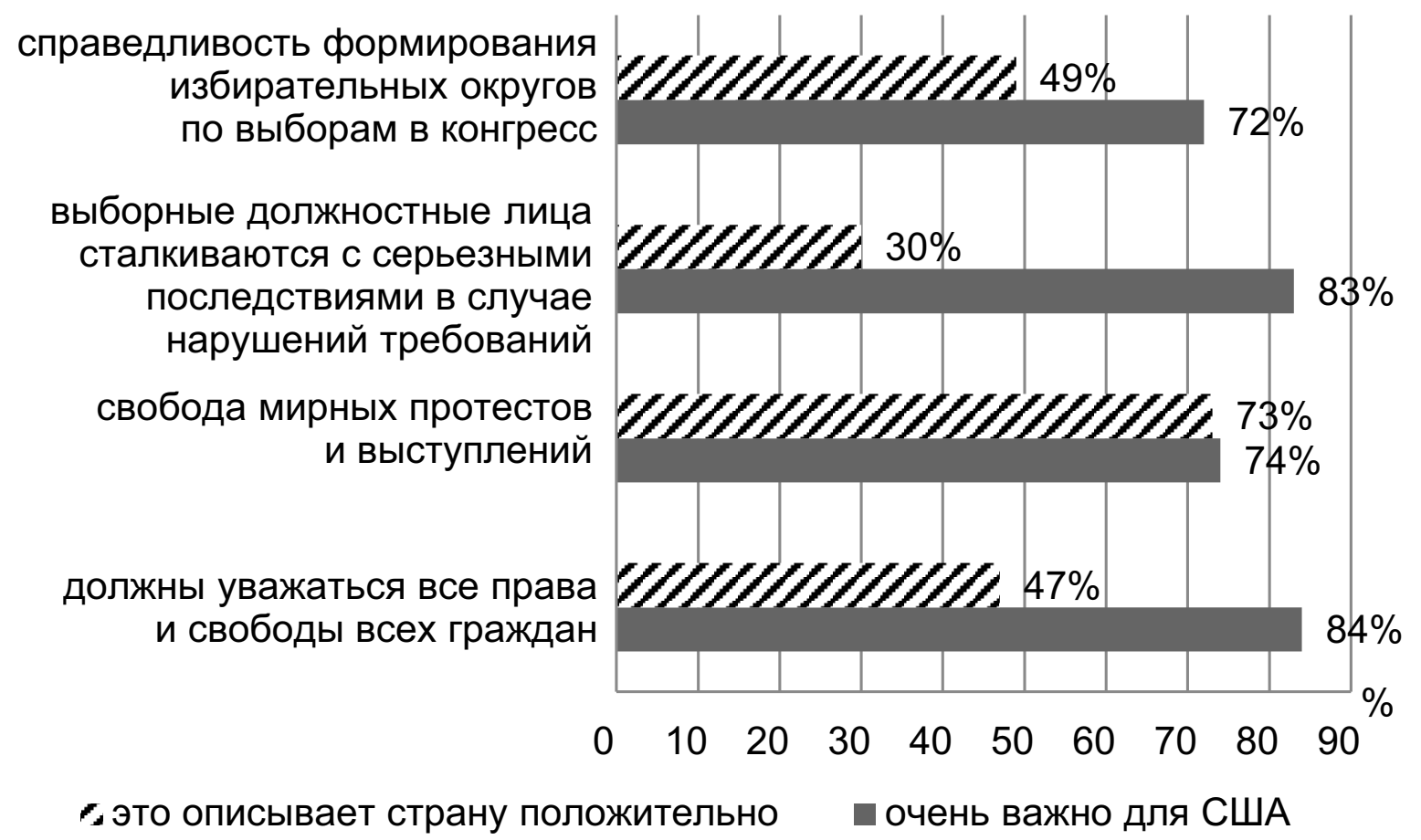

Рис. 1. Демократия в США: идеи и ценности. Исследование "Pew center" USA. 2018. $\mathrm{N}=4656^{15}$

Большинство респондентов США отмечает, что Президенту Д. Трампу не хватает уважения к демократическим институтам. Менее половины опрошенных респондентов (45\%) фиксируют, что Дональд Трамп уважает демократические институты и традиции страны, а 54\% говорят, что он “не слишком уважает” и “не уважает" демократические институты и традиции США. Эти концептуальные расхождения во взглядах простых американцев раскололи общество по партийно-политическим и идеологическим признакам. Большинство респондентов среди консервативных республиканцев (55\%) отмечают, что Д. Трамп в “большей” степени уважает демократические институты страны; большинство либеральных демократов (60\%) говорят, что он “вообще не уважает” эти традиции и институты.

Важным выводом является то, что респонденты отмечают рост эффективности организации работы правительства США и федеральных политиков в целом, но не на местном уровне. При этом значительное число респондентов США положительно оценивает

${ }^{15}$ The public, the political system and American democracy. 
деятельность местного правительства (на уровне штатов) - 67\%, а не федерального правительства (35\%). Кроме того, есть существенное удовлетворение респондентов США качеством кандидатов, баллотирующихся в Конгресс и на местных выборах. При этом данные демонстрируют определенное противоречие в оценках недавних кандидатов в президенты: так, только $41 \%$ респондентов отмечает, что качество кандидатов в президенты на последних выборах в США было “достойным”.

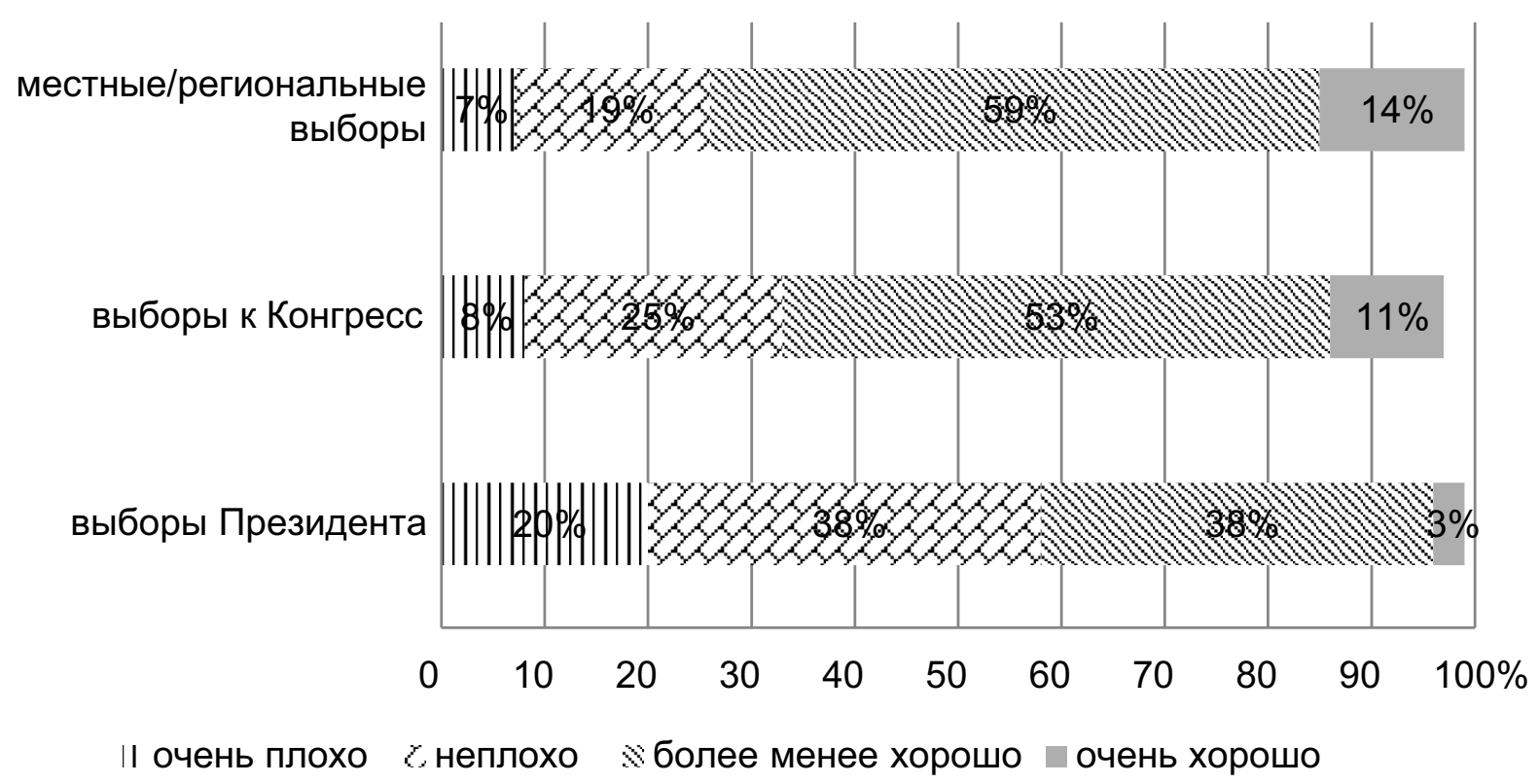

Рис. 2. Представления о качествах кандидата на выборах. Исследование "Pew center" USA. 2018. $\mathrm{N}=4656^{16}$

Результаты исследования показывают негативные оценки тональности политической дискуссии на последних президентских выбо$\operatorname{pax}^{17}$. Только четверть американцев говорят, что “тон дебатов среди политических лидеров является уважительным” и этот показатель положительно описывает политическую систему страны. Тем не менее, общественность более высоко оценивает общие взгляды на тональность и дискурс политического процесса: 55\% опрошенных американцев говорят, что слишком много людей “легко обижаются” из-за языковых особенностей и тональности СМИ, которые используются в выборной полемике; $45 \%$ респондентов отмечают, что общество должно быть более осторожным в использовании особенностей и тональности выражений, чтобы “не обидеть” иных участников в процессе полемики.

\footnotetext{
16 The public, the political system and American democracy.

${ }^{17}$ Ibid.
} 


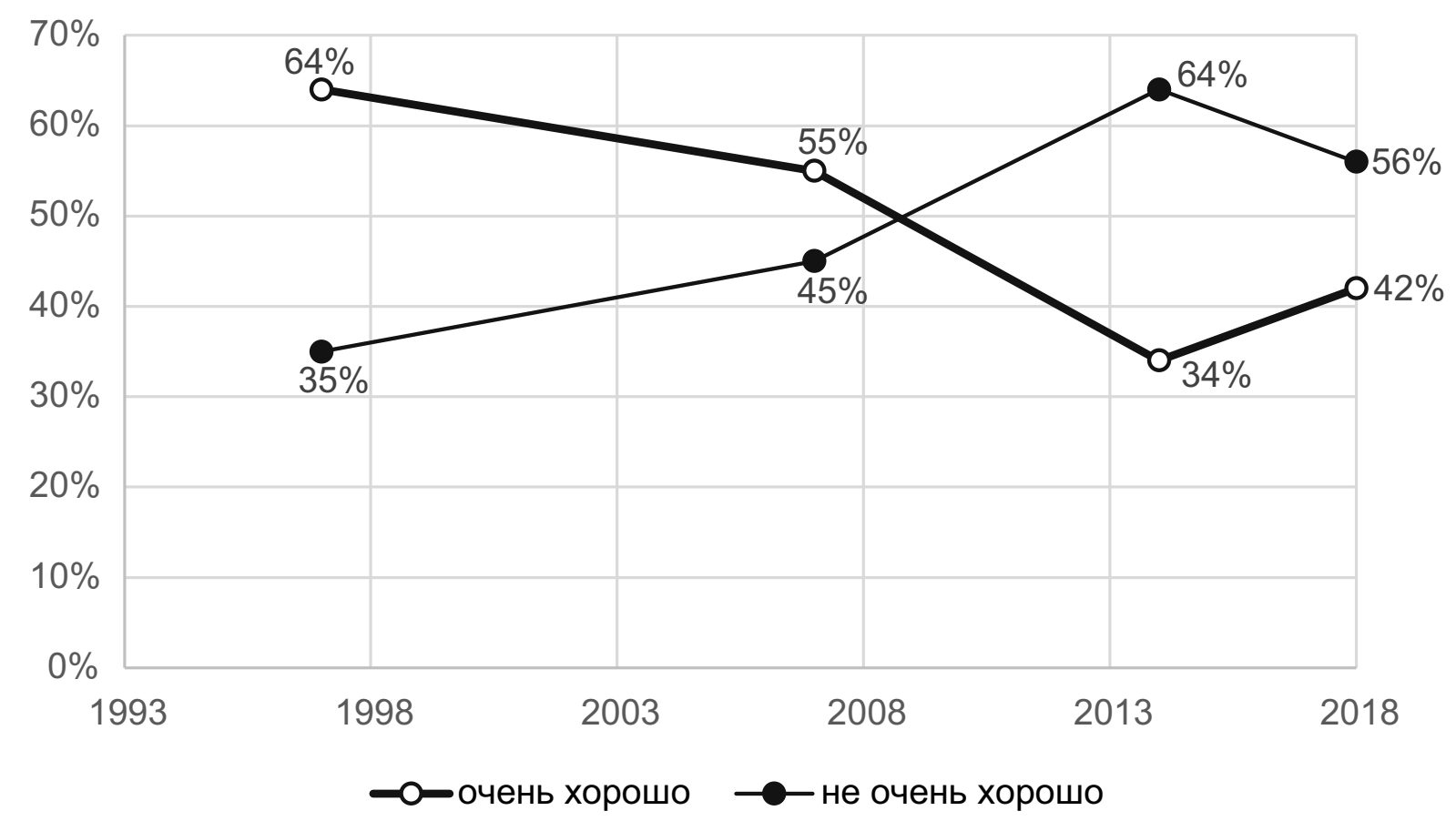

Рис. 3. Оценка уверенности и политического здравого смысла избирателей США. Исследование “Pew center" USA. 2018. N=4656

Результаты исследования также демонстрируют осознание американским обществом объективного наличия необходимой критики. Обращаясь к недостаткам политической системы, американцы выделяют и ряд критических факторов: только 39\% респондентов говорят, что “избиратели осведомлены о кандидатах и проблемах", что общество “очень хорошо” или “в недостаточной степени хорошо" осведомлено о кандидатах и проблемах. Кроме того, большинство респондентов (56\%) подчеркивает, что “в меньшей степени” или “совсем не уверены” в политической объективности (мудрости) как общества в целом, так и “простого” американца. Тем не менее, это процесс снижения негативных оценок, которые были зафиксированы в начале 2016 г., когда 64\% респондентов были “в меньшей степени уверенности" или зафиксировали отсутствие уверенности в политической объективности общества. После президентских выборов респонденты из партии республиканцев стали более уверенными в политической объективности общества ${ }^{18}$.

Исследование также продемонстрировало, что большинство респондентов США уверено в наличии значительного политического влияния у тех, кто жертвует больше денег на выборы. Подавляющее большинство (77\%) поддерживает ограничения на объемы политических пожертвований, которыми отдельные представители общества и организации могут профинансировать избирательные

18 The partisan divide on political values grows even wider. 
кампании. И почти две трети респондентов (65\%) считают, что новое законодательство может быть эффективным в снижении роли пожертвований (денег) в американском политическом процессе.

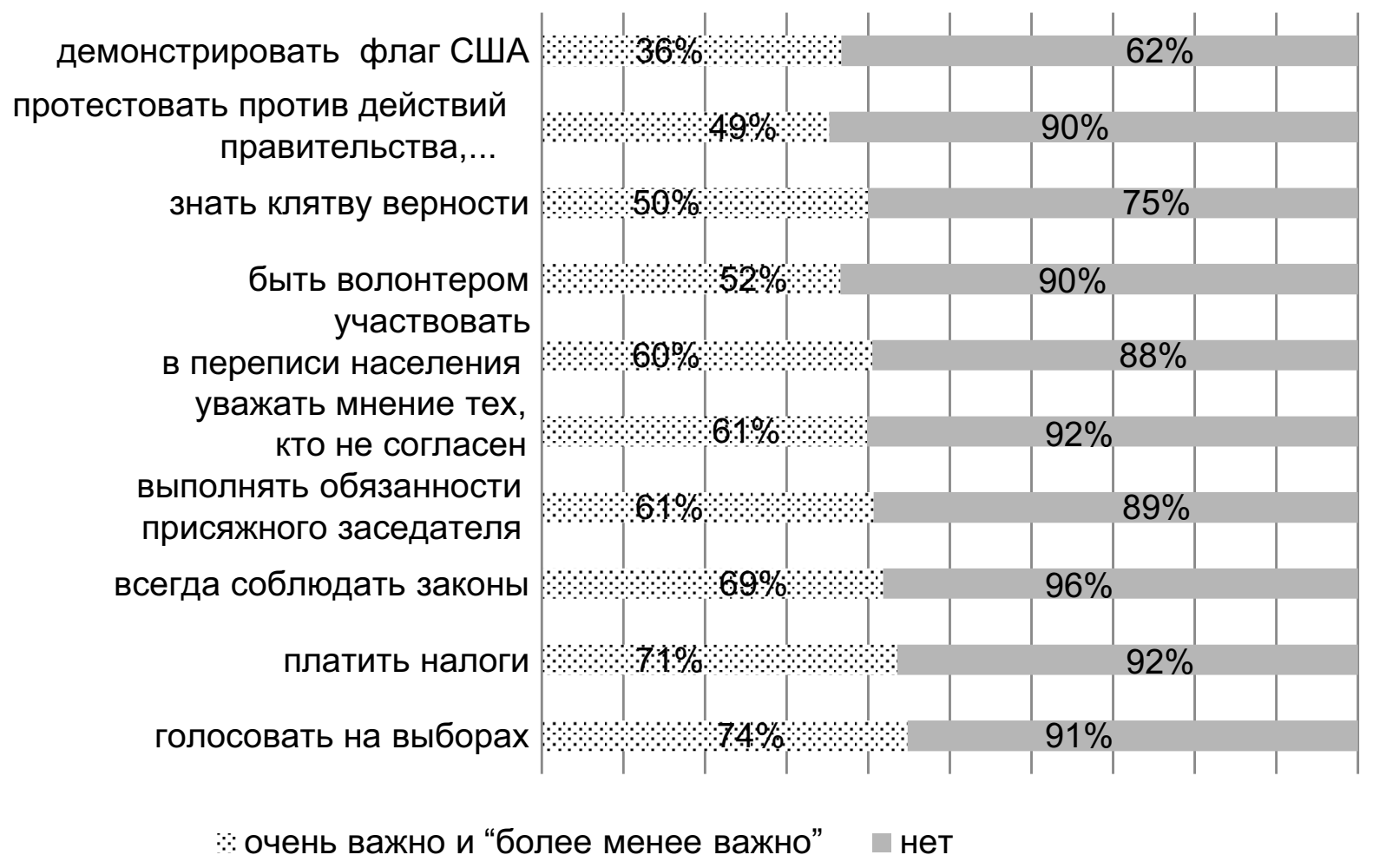

Рис. 4. Важность приоритетов для “хорошего" гражданина США. Исследование "Pew center" USA. 2018. N=4656 ${ }^{19}$

Преобладающее большинство респондентов подчеркивает, что очень важно участвовать в голосовании/избирательном процессе, пользоваться правом голоса, платить налоги и всегда соблюдать требования законов, что и означает быть “хорошим гражданином”. Половина простых американцев отмечает, что очень важно знать клятву верности, 45\% говорят, что очень важно протестовать против действий правительства, если они, по мнению простого американца, являются неправильными. 36\% респондентов подчеркнули, что демонстрация американского флага является важным признаком “хорошего гражданина своей страны”.

Большинство респондентов подчеркивает свои знания об основных фактах, о политической системе и демократии в США. Подавляющее большинство правильно определяет понятия конституционного права, гарантированные Первой поправкой к Конституции, знает роль Коллегии выборщиков в США. Меньшее количество респондентов знает, как голосует Сенат США, менее половины имеет

19 The public, the political system and American democracy. 
представление о количестве голосов, необходимых для того, чтобы получить большинство в Сенате.

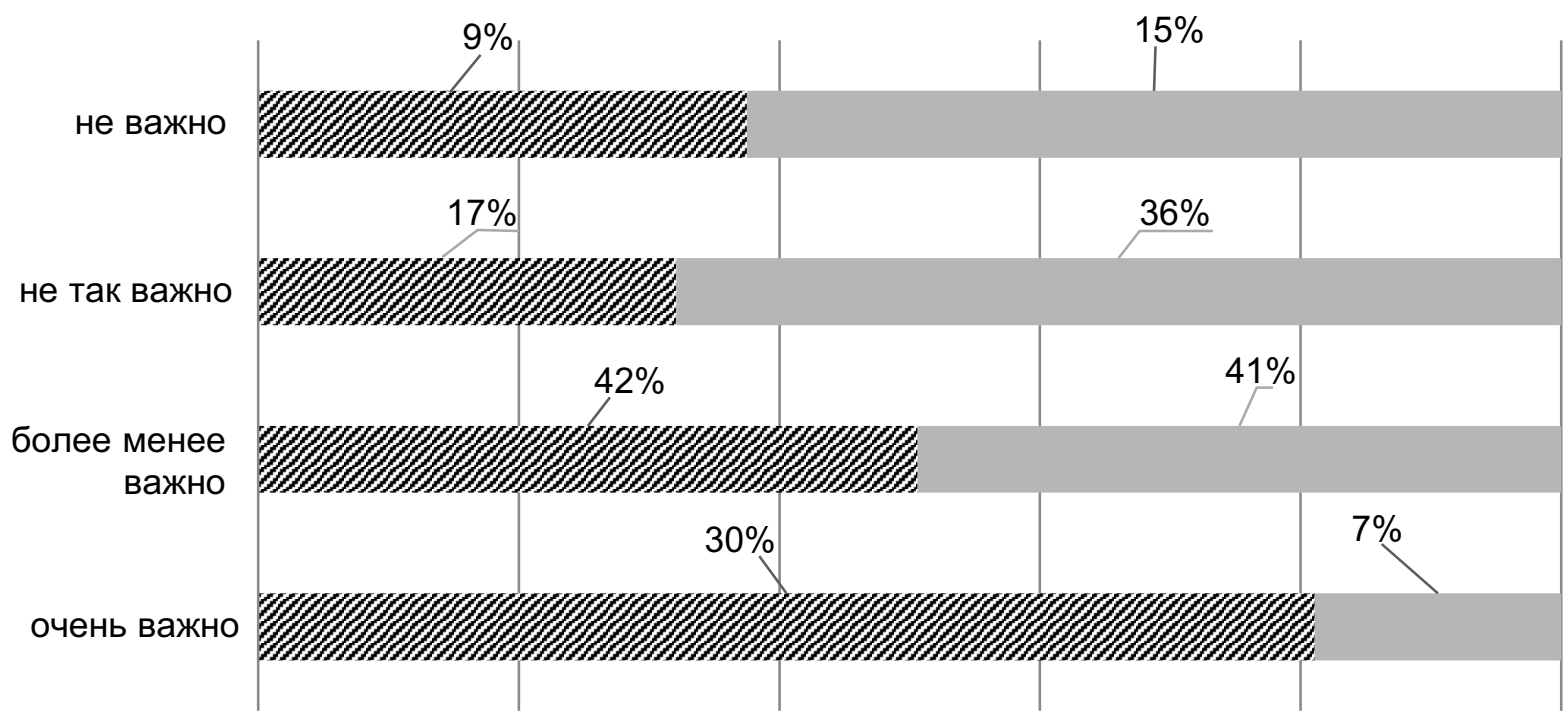

z республиканцы и сторонники республиканцев демократы и сторонники демократов

Рис. 5. Большинство демократов одобряют серьезные изменения в организации исполнительной власти - Правительства.

Исследование “Pew center" USA. 2018. N=4656

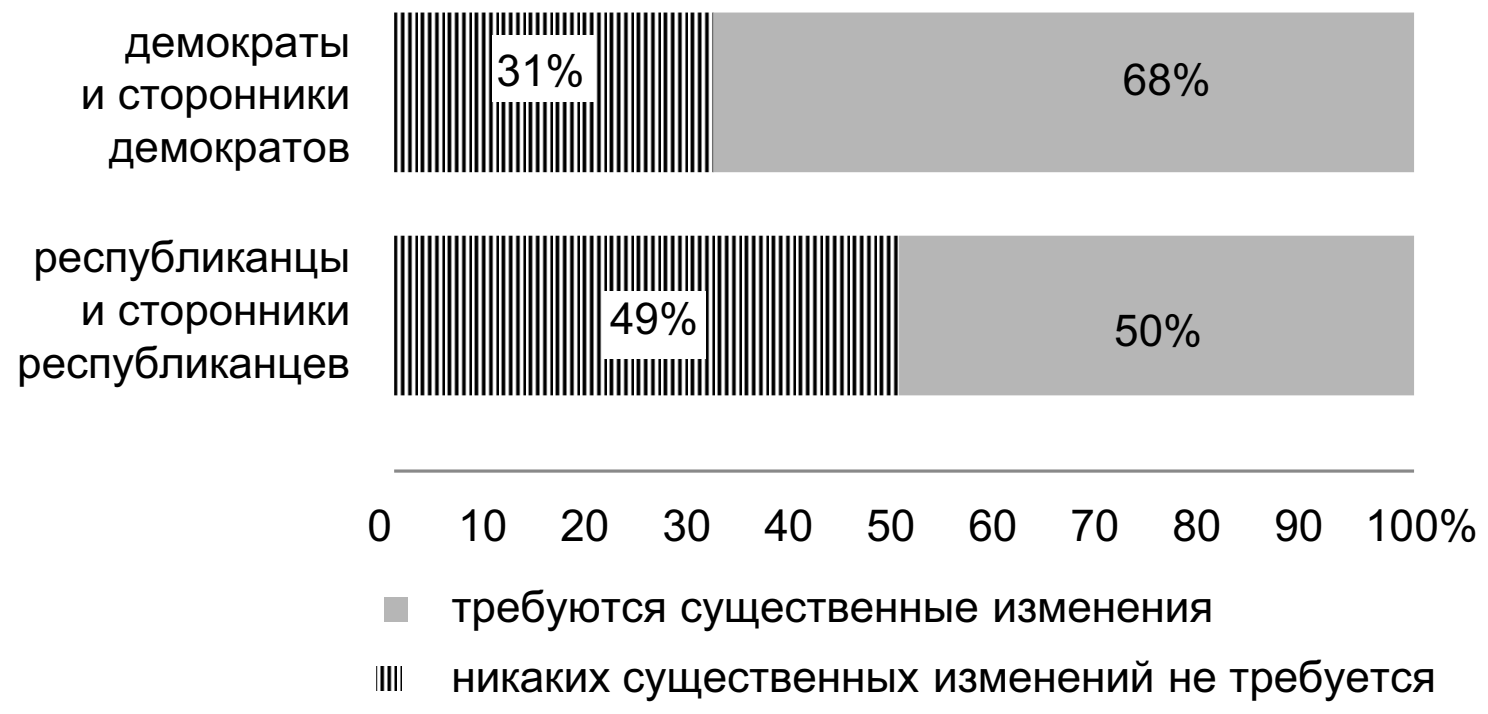

Рис. 6. Мнения респондентов об изменении правительства США. Исследование "Pew center" USA. 2018. N=4656

В целом, большинство респондентов считает, что демократия США работает, по крайней мере, “в большей степени хорошо”. Тем не менее, большинство опрошенных (61\%) говорит, что необходимы “значительные изменения” в фундаментальной структуре органов исполнительной власти американского правительства, чтобы оно эффективно работало в нынешнее время. Когда просят респондента сравнить политическую систему США с политическими системами 
других развитых стран, менее половины оценивают ее как “выше среднего” или “лучшую в мире”.

Исследования демонстрируют, что две трети американцев (58\%) дают высокие оценки функционированию демократических институтов в США - сумма оценок “очень хорошо” или “несколько хорошо”, из них 18\% респондентов отмечают, что демократия в США работает “очень хорошо”.

Респонденты, относящиеся к сторонникам республиканцев, имеют более позитивное мнение о демократии США, чем респонденты-демократы: 72\% сторонников республиканцев считают, что демократия в США работает, по крайней мере, “в большей степени хорошо”, из них 30\% опрошенных говорят, что демократические институты работают “очень хорошо”. Среди демократов и сторонников демократов 48\% подчеркивают, что демократия в США работает, “несколько хорошо”, и 7\% из них говорят, что она функционирует “очень хорошо”.

Проведенный анализ позволяет говорить, что среди демократов чаще, чем среди сторонников республиканцев, раздаются голоса поддержки необходимости существенных изменений в структуре государственного управления и структуры правительства США: так, оценки разнятся более чем в два раза (68 к 31\%). Респонденты-демократы отмечают, что необходимы значительные изменения. Мнения респондентов-республиканцев разделились поровну: 50\% считают, что в структуре правительства необходимы значительные изменения, а 49\% считают, что нынешняя структура государственного управления “хорошо” отражает национальные задачи страны и не нуждается в значительных изменениях.

Общественное мнение по-разному оценивает политическую систему США по сравнению с оценками других развитых стран. Примерно четыре из десяти опрошенных подчеркивают, что политическая система США является лучшей в мире (15\%) или уровень “выше среднего” (26\%); большинство американцев ставит политической системе США средние оценки (28\%) или ниже среднего (29\%) по сравнению с другими развитыми странами. Прочие национальные институты и общественные организации США, в том числе военные, а также уровень жизни и научно-технические достижения получают более высокую оценку респондентов, чем функционирующая политическая система.

Результаты социологического опроса зафиксировали, что респонденты среди республиканцев примерно в два раза чаще, чем среди демократов, отмечали однозначное преимущество политической системы США: то, что она является лучшей в мире или ее уровень 
“выше среднего” (58 против 27\%). Подобных дифференцированных оценок и пристрастий в 2012 г. в общественных мнениях американцев не было зафиксировано.

В заключение необходимо констатировать сложность происходящих внутриполитических процессов в США, наличие существующих противоречий и раскол общественного мнения относительно стабильности демократических механизмов функционирования политической системы США. Сложность религиозных, национальных, социальных и иных противоречий общественного развития подняла на поверхность общественных дискуссий комплекс проблем динамики политического развития и государственного механизма управления. Подобной дифференциации политического фона общественных дискуссий в США ранее исследователями не наблюдалось, что в настоящее время является богатой почвой как для анализа происходящих в американском обществе процессов, так и для взвешенной оценки состояния социально-политической сферы США.

\section{СПИСОК ЛИТЕРАТУРЫ}

Миронюк М.Г. Современный федерализм. Сравнительный анализ. М., 2008.

\section{REFERENCES}

Azari J., Masket S. The 4 types of constitutional crises // ABS News. 2017. 09 Febr. URL: https://fivethirtyeight.com/features/constitutional-crisis/ (accessed: 30.12.2018).

Mironyuk M.G. Sovremennyj federalizm. Sravnitel'nyj analiz [Modern federalism. Comparative analysis]. M., 2008 (in Russian).

Quigley C.N. Constitutional democracy // Center for Civic Education. 2018. URL: http://www.civiced.org/resources/publications/resource-materials/390-constitutionaldemocracy (accessed: 09.01.2019).

Sargent $G$. An uncivil war: taking back our democracy in an age of Trumpian disinformation and thunderdome politics. N.Y., 2018.

Stokes S.C., Clayton K.P., Helmke G. American democracy after Trump's first year // Bright Line Watch. 2018. 8 Febr.

Stone $T$. The Trump kleptocracy. The presidency is officially a cash grab - and a pitstop on the way to autocracy // Medium Politics. URL: https://medium.com/s/story/ the-trump-kleptocracy-969c3ef9b4b3 (accessed: 30.12.2018).

The partisan divide on political values grows even wider // Trust, Facts, and Democracy. Pew Research Center. URL: http://www.people-press.org/2017/10/05/the-partisandivide-on-political-values-grows-even-wider/ (accessed: 09.01.2019).

The public, the political system and American democracy // Trust, Facts, and Democracy. Pew Research Center. URL: http://www.people-press.org/2018/04/26/the-publicthe-political-system-and-american-democracy/ (accessed: 09.01.2019).

Wike R., FetterolfJ. Liberal democracy's crisis of confidence // Journal of Democracy. 2018. N 29 (4). P. 136-150. 